\title{
Laboratório de Robótica Inclusiva: Robótica Educacional e Raciocínio Computacional no Ensino Médio
}

\author{
Ana Carolina Sokolonski ${ }^{1}$ \\ ${ }^{1}$ Grupo de Pesquisa em Sistemas Embarcados, Controle e Eficiência Energética (GSECEE) \\ Departamento Acadêmico de Computação \\ Instituto Federal de Educação, Ciência e Tecnologia da Bahia (IFBA) \\ carolsoko@ifba.edu.br
}

\begin{abstract}
Educational Robotics (ER) emerged from the theories of Constructivism and Constructionism, arguing that through the construction of robotic artifacts, students can develop essential skills, such as Computational Thinking $(C T)$. Recently, the CT became part of one of the ten competencies of Basic Education in the National Common Curricular Base of Brazil (BNCC). In this article, we describe the project Inclusive Robotics Laboratory, aimed to teach ER to high school students and thus improving their CT. In the project, we developed tutorials in Robotics and Programming to help students build line follower robots, as well as enabling them to participate in robotics competitions. As a result, in addition to the personal development of the students involved, an online teaching platform was made available, with video lessons, scripts, and teaching materials.
\end{abstract}

Resumo. A Robótica Educacional (RE) surgiu a partir das teorias do Construtivismo e Construcionismo, defendendo que através da construção de artefatos robóticos, os alunos podem desenvolver habilidades essenciais, como o Raciocinio Computacional (RC). Recentemente, o RC passou a integrar uma das dez competências do Ensino Básico na Base Nacional Comum Curricular (BNCC). Neste artigo, será descrito o trabalho intitulado Laboratório de Robótica Inclusiva, que teve como premissa ensinar RE aos alunos do Ensino Médio com o intuito de aprimorar o RC. Neste projeto, foram desenvolvidas capacitações na área de Robótica e Programação para construção de robôs seguidores de linha, assim como participação em competições de robótica. Como resultado, além do desenvolvimento intelectual dos alunos envolvidos, uma plataforma de ensino online foi disponibilizada, com vídeo-aulas, roteiros e materiais didáticos.

\section{Introdução}

Em 2006, Jeannette Wing apresentou à comunidade acadêmica o termo Raciocínio Computacional (RC), conceito que existia há muitos anos, mas nunca havia sido descrito, nomeado e colocado em evidência como Wing fez em seu trabalho [Wing 2006]. Para Wing, RC é um conhecimento fundamental para todos, não apenas para os cientistas da computação.

O RC é uma forma organizada de raciocinar, que pode ser treinada desde os primeiros anos de vida da criança, tornando natural essa forma de pensar 
[França and Tedesco 2015]. O RC envolve desenvolvimento de habilidades de matemática, raciocínio lógico, abstração, decomposição e generalização de problemas, entre outras. O desenvolvimento do RC auxilia a execução de atividades do cotidiano, que não necessariamente envolvem computação, pois raciocinar de forma organizada, proporcionando a otimização de tarefas e tomadas de decisão, facilitando a resolução de problemas, é útil para todos [Wing 2008].

A Robótica Educacional (RE) surgiu a partir das teorias do Construtivismo de Jean Piaget [Piaget 1976] e do Construcionismo de Seymour Papert [Papert 1980]. Papert acreditava que a criança aprende durante a criação de artefatos e experimentação de suas teorias. Em [Papert et al. 1986], Papert criou a linguagem de programação Logo ${ }^{1}$, permitindo que as crianças controlassem um dispositivo robótico, através de comandos básicos da linguagem, desenvolvendo o RC de forma lúdica e reflexiva. A RE, portanto, consiste em trabalhar com os alunos conteúdos curriculares através da construção e manipulação de robôs, seja de forma virtual ou física, possibilitando que a criança construa o seu conhecimento através da construção de algo palpável.

A RE incentiva os alunos a pesquisar, experimentar e solucionar problemas, que geralmente são ligados ao mundo real. Desta forma, a RE contribui de forma significativa para o desenvolvimento de habilidades e competências, tais como: raciocínio lógico, formulação e teste de hipóteses, relações interpessoais, investigação e compreensão de problemas, resolução de problemas por meio de erros e acertos, criatividade e capacidade autocrítica, entre outras. Segundo pesquisas recentes, os alunos têm se mostrado interessados e empolgados na participação de atividades de RE [Díaz-Lauzurica and Moreno-Salinas 2019, Oliveira et al. 2019]. "A Robótica Educacional tem como principal característica um ambiente de aprendizagem no qual os alunos podem montar, programar e analisar o comportamento de um robô" [Cambruzzil and Mendes de Souza 2014, pag 3].

O desenvolvimento do RC através da RE acontece de forma intuitiva, desenvolvendo habilidades à medida que os alunos participam das atividades de robótica e constroem os artefatos. Neste processo, algumas das habilidades desenvolvidas são: análise de problemas, abstração e decomposição dos problemas, planejamento e desenvolvimento de soluções, generalização das soluções, trabalho em equipe, realização de consenso, aprimoramento constante das soluções propostas, auto-análise e auto-crítica, entre outras. $\mathrm{O}$ RC se destaca pela capacidade de resolução de problemas complexos através da abstração, decomposição e sistematização da solução, que leva à simplificação do problema, que é uma competência útil para todas as pessoas, e no campo da RE é imprescindível para se alcançar soluções eficazes.

Com o objetivo de ensinar RC aos alunos do ensino médio técnico através da RE, avaliando a eficácia da proposta, foi-se realizado, dentro do Instituto Federal de Educação, Ciência e Tecnologia da Bahia (IFBA) - Campus Salvador, um projeto intitulado Laboratório de Robótica Inclusiva (LRI). Neste artigo, será relatada a experiência empírica realizada com três alunos, que culminou num arcabouço de material de estudo disponibilizado no site do projeto $^{2}$.

\footnotetext{
${ }^{1}$ https://el.media.mit.edu/logo-foundation/index.html

${ }^{2}$ www.sokolonski.com.br
} 
O artigo está organizado da seguinte forma, na Seção 2, será apresentada uma revisão bibliográfica sobre o estado da arte do ensino de RC e RE para alunos do ensino médio. Na Seção 3, será apresentada a metodologia utilizada. Em seguida, o projeto LRI será apresentado na Seção 4, sendo explicados, detalhadamente, o módulo Laboratório de Computação Inclusiva (LCI), na Subseção 4.1, e o módulo Construção de Robô Seguidor de Linha (CRSL), na Subseção 4.2. Os resultados alcançados serão apresentados na Seção 5 e, por fim, a conclusão do trabalho será apresentada na Seção 6.

\section{Trabalhos Relacionados}

Nesta seção, será apresentada uma breve revisão bibliográfica, realizada com o intuito de investigar o estado da arte e a viabilidade de desenvolver o Raciocínio Computacional (RC) dos alunos do ensino médio através da Robótica Educacional (RE).

Em [Dargains and Sampaio 2015], os autores apresentam um estudo empírico envolvendo a RE, a abordagem construcionista e a Taxonomia de Bloom Revisada, com o objetivo de avaliar os possíveis ganhos do uso da RE no ensino de programação introdutória para alunos do Ensino Médio sem conhecimento prévio de programação. A pesquisa foi conduzida com alunos do Ensino Médio de escolas públicas e, comparando com uma disciplina de programação oferecida por uma universidade federal local, os alunos apresentaram satisfatório aprendizado e desempenho.

Em [Oliveira and Araujo 2016], os autores realizaram oficinas de robótica com alunos do $1^{\circ}$ ano do ensino médio, com idades entre 15 e 16 anos, para avaliar como o RC pode ser estimulado nesta faixa etária. Os autores aplicaram métricas de avaliação, realizando pré-testes e pós-testes em grupos focais e chegaram à conclusão que a RE pode potencializar o aprendizado do RC.

Em [Schuhmacher and Schuhmacher 2017], os autores apresentaram uma proposta metodológica, baseada nos pressupostos da aprendizagem significativa, para o ensino de RC no Ensino Médio, incorporando a RE em um cenário flexível, chamado Clube da Robótica. Os resultados obtidos pelos autores mostram o interesse dos alunos em discutir conceitos científicos, desenvolvimento de habilidades de colaboração e interação do $\mathrm{RC}$, e assimilação de conceitos curriculares diversos.

Em [Phadung et al. 2018], os autores fizeram um estudo empírico com 90 estudantes do Ensino Médio, com idades entre 16 e 17 anos, para avaliar se o RC era viável de ser ensinado através da RE. Após fazer as atividades de RE usando Arduino, avaliando o desempenho e satisfação dos estudantes, os autores chegaram a conclusão que os alunos se sentiram bastante motivados com o uso da robótica e que as habilidades do RC puderam ser alcançadas.

Em [Díaz-Lauzurica and Moreno-Salinas 2019], os autores realizaram uma experiência prática cujo objetivo era ensinar $\mathrm{RC}$ usando $\mathrm{RE}$ a uma turma de alunos do 3a ano do Ensino Médio, que apresentavam alto grau de apatia e desmotivação. Além das aulas de RE, foi realizado um treinamento em RC usando gamificação, que contribuiu para aumentar visivelmente a motivação dos alunos. Os resultados mostraram que houve um aumento na motivação dos alunos, alcançando uma aprendizagem significativa.

Em [Santos et al. 2019], os autores realizaram oficinas de programação e RE com 71 meninas do $1^{\circ}$ ao $3^{\circ}$ anos do Ensino Médio. O intuito era estimular o RC e aproximá- 
las da área de computação. Como conclusão, os autores ponderam que as meninas se sentiram motivadas a ingressarem na área de tecnologia, e, acreditam que a área de tecnologia, com ações como estas, tende a ser mais igualitária.

Como pode ser observado, trabalhos foram realizados com o intuito de desenvolver o RC dos alunos através da RE, focando em alunos do Ensino Médio. A maioria relata que obtiveram êxito nos experimentos, demonstrando que alunos nessa faixa etária e nível de ensino têm capacidade de realizar atividades de RE, além de conseguirem aprender habilidades de RC durante o processo, precisando apenas de conhecimentos básicos, recursos e orientação. Em consonância com os trabalhos supracitados, este artigo apresenta um relato de experiência da aplicação de RE com o intuito de desenvolver o RC de alunos do Ensino Médio Técnico.

\section{Metodologia}

A metodologia aplicada neste projeto alternou entre aulas expositivas e aulas práticas, como realizado em [Cambruzzil and Mendes de Souza 2014], utilizando procedimentos metodológicos nos quais o uso da tecnologia auxiliou na construção e explicitação do conhecimento. Os aprendizes tiveram, inicialmente, aulas expositivas e práticas de lógica de programação, obtendo acesso a conhecimento e tecnologia durante todo o projeto, e em seguida aulas de programação em Arduino e construção de Robôs.

Os alunos tiveram acesso livre ao laboratório de experimentos e aos materiais (computadores, diversos tipos de Arduinos, pontes H, componentes eletrônicos, ferramentas, diversos tipos de rodas, pistas de corrida, impressora 3D, entre outros), possibilitando que os alunos praticassem o que aprenderam testando diferentes configurações de robôs. Além disso, a participação em competições e mostras de robótica foram usadas como recurso motivacional, como realizado por [de Souza Pio et al. 2006]. Assim, à medida que os alunos participavam de competições e mostras, adquiriam experiência, sentiam-se empolgados, trocavam informações com outros competidores e amadureciam suas decisões quanto ao design do robô que eles estavam desenvolvendo.

A avaliação de desempenho foi feita através de pré-testes e pós-testes, como realizado em [Phadung et al. 2018], envolvendo questões de lógica de diversos níveis, além de entrevistas com os alunos, para avaliar a motivação e a possibilidade de melhoramentos das ações, além da observação da evolução intelectual, visando aspectos quantitativos e qualitativos, como realizado em [Oliveira and Araujo 2016]. Dois alunos iniciaram o projeto sem conhecimento de lógica de programação ou robótica, o terceiro aluno tinha conhecimento prévio de lógica de programação, mas não havia trabalhado com robótica. Os resultados alcançados serão detalhados na Seção 5.

\section{Laboratório de Robótica Inclusiva}

O Laboratório de Robótica Inclusiva (LRI) foi um projeto desenvolvido no Instituto Federal de Educação, Ciência e Tecnologia da Bahia (IFBA) - Campus Salvador, para os alunos do ensino médio técnico, durante o ano letivo de 2019. O objetivo principal do projeto era auxiliar os alunos no processo de aprendizado de Raciocínio Computacional (RC), através do ensino de conteúdos da área de computação e robótica, disponibilizando em seguida o material de estudo para comunidade. O projeto contou com a participação de 3 alunos do ensino médio técnico, sob orientação da professora coordenadora. A 
culminância do projeto, através do registro das etapas de construção do robô e desenvolvimento de material didático, foi a construção de um arcabouço de material didático online, disponibilizado gratuitamente, que ensina passo-a-passo todo o conteúdo teórico passado aos alunos durante o projeto.

O LRI mostra como construir um robô seguidor de linha com componentes básicos e baratos, como a placa de Hardware livre Arduino, como controlá-lo e deixá-lo funcional para participar de competições, e disponibiliza um curso básico de lógica de programação, que passou a ser um módulo do projeto nomeado Laboratório de Computação Inclusiva (LCI) e será descrito na Subseção 4.1.

A iniciativa de disponibilizar um arcabouço online partiu da alta demanda dos alunos do IFBA em participar de projetos como o LRI, no intuito de aprender Robótica Educacional (RE) e Raciocínio Computacional (RC). Assim, o arcabouço online possibilita que os conhecimentos sejam acessíveis a todos os alunos interessados em aprender RE e RC, inclusive, alunos com deficiências cognitivas, que através da construção de robôs, poderão entender melhor, de forma lúdica e descomplicada, assuntos de RE e RC, além de terem a possibilidade de repetir a leitura ou assistir as vídeo-aulas quantas vezes precisar para sua total compreensão, levando o tempo que for necessário para seu aprendizado.

Outra ação tomada no âmbito do projeto LRI foi a criação de um módulo exclusivo sobre a criação do robô, intitulado Construção de Robô Seguidor de Linha (CRSL), ver Subseção 4.2. Neste módulo foi realizada a disponibilização de material de estudo de robótica de baixo custo, em estilo Maker, ou seja, com a criação do Chassi e demais componentes feita pelos próprios alunos, usando materiais acessíveis, para que os demais alunos do ensino médio possam se motivar a construir sozinhos seus próprios robôs, participar de competições de robôs e realizar atividades na área de RE e RC.

Ambos os módulos, tanto o LCI quanto o CRSL, têm por objetivo o desenvolvimento do RC do aluno. O primeiro, foca no ensino de RC através da lógica de programação, culminando em vídeo-aulas, roteiros de aulas e materiais diversos de ensino de lógica de programação. $\mathrm{O}$ segundo, ensina $\mathrm{RC}$ através da $\mathrm{RE}$, com foco na construção de um robô seguidor de linha, culminando em roteiros de aulas ensinando como construir o robô, com detalhes de funcionamento das partes do mesmo. Os módulos do LRI estão disponíveis gratuitamente no site do projeto ${ }^{3}$.

\subsection{Laboratório de Computação Inclusiva}

O Laboratório de Computação Inclusiva (LCI) é um módulo do projeto LRI. O LCI consistiu em um treinamento para os alunos bolsistas, com aulas práticas e teóricas, que culminou numa série de vídeo-aulas sobre lógica de programação, visando o ensino mais aprofundado da construção de algoritmos, material didático relacionado, roteiros de aulas e arquivos fonte, disponibilizados no site do projeto.

As vídeo-aulas foram gravadas por um dos alunos bolsistas, sob orientação da professora. Inicialmente, o projeto foi desenvolvido com o foco no ensino de lógica de programação aos alunos do $1^{\circ}$ ano do ensino médio técnico do IFBA, cobrindo o conteúdo da disciplina de Informática dos cursos técnicos em Eletrônica e Automação Industrial, porém, como ganhou um caráter mais amplo ao abordar assuntos básicos de disciplinas de

\footnotetext{
${ }^{3}$ WwW.sokolonski.com.br
} 
Introdução a Lógica de Programação do ensino superior, passou a ser disponibilizada no site do projeto para acesso de qualquer pessoa que queira aprender a programar computadores ou dispositivos embarcados, que utilizem o Arduino ou RaspberryPI, por exemplo.

O curso online teve o roteiro idealizado pela professora e aplicado pelo aluno bolsista participante, o qual explica o conteúdo programático aprendido por ele na disciplina. O LCI conta também com roteiros de aulas de assuntos mais avançados, como algoritmos de ordenação, podendo o aprendiz se aprofundar no estudo. Foram disponibilizados também materiais didáticos, como os slides usados nas aulas e arquivos fonte com os exemplos dados nas vídeo-aulas, além dos arquivos fonte que a professora utiliza em suas aulas, que estão comentados, com perguntas e respostas, facilitando o estudo e entendimento dos algoritmos.

O LCI auxilia o desenvolvimento do RC na medida em que ensina lógica de programação focando nas habilidades do RC, como abstração, decomposição e generalização, estimulando o raciocínio lógico do aluno. $\mathrm{O}$ formato do curso é adequado para alunos em todos os níveis de conhecimento, inclusive os que nunca tiveram nenhum contato com programação de computadores, pois ensina lógica de programação, inicialmente, através de Linguagem de Programação Portugol e fluxogramas, facilitando o contato dos aprendizes que não dominam a língua inglesa, por exemplo.

\subsection{Construção de Robô Seguidor de Linha}

O módulo Construção de Robô Seguidor de Linha (CRSL) foi desenvolvido com base na fase de aquisição de conhecimentos básicos de robótica dos alunos, que após aprender a desenvolver um algoritmo, precisavam aprender a construir um robô. Para tanto, os alunos tiveram que estudar e aprender como funciona os componentes do robô (Hardware livre Arduino, a ponte $\mathrm{H}$, as rodas, entre outros), além de desenvolvimento de algoritmos para o controle do Arduino, que utiliza Linguagem de Programação Arduino, que não foi abordada no módulo LCI, tendo uma correlação criada no módulo CRSL.

Os alunos envolvidos no projeto vivenciaram a experiência no estilo Maker, ou seja, aprenderam enquanto construíam o robô, passo-a-passo, para participar de competições de corrida no formato Seguidor de Linha. As competições de robótica da categoria Seguidor de Linha exigem que o robô seja autônomo, sem utilização de controle remoto ou qualquer recurso de controle, devendo percorrer uma pista de corrida, sem sair do trajeto, parando sozinho ao seu término. O carro que percorrer mais rapidamente a pista ganha a competição.

A pista da competição possui apenas duas cores, preto e branco, ou a pista é preta com o trajeto a ser percorrido em branco, ou vice versa, como pode ser visto na Figura 1. O material da pista varia muito de competição para competição. Algumas competições possuem pista de fórmica e outras de borracha, por exemplo, o que interfere no desempenho do carro, no tipo do material da roda, no nível de aceleração de partida do carro, tempo de parada, desgaste da bateria, entre outros fatores. Algumas competições têm iluminação precária, outras são muito iluminadas, o que interfere na regulagem dos sensores. Algumas competições têm restrições de tempo e tamanho de pistas diferentes, curvas mais acentuadas, ladeiras, obstáculos, limitação na possibilidade de manutenção dos carros, no contato com os professores orientadores, entre outras. Assim, as competições são sempre desafiadoras e permitem que os alunos evoluam bastante durante sua 
execução.

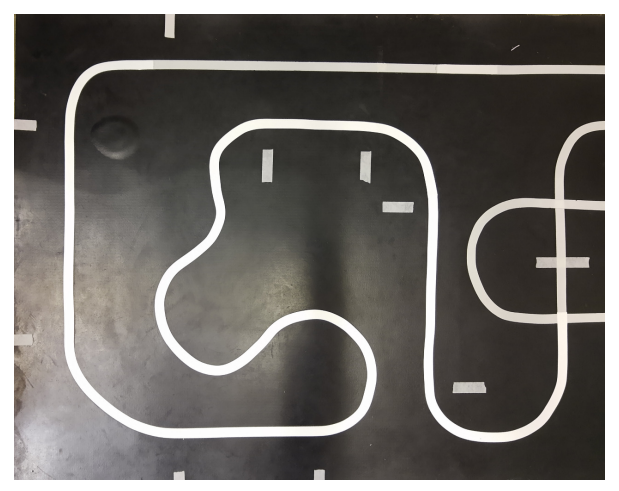

Figura 1. Pista de Testes do Projeto

Além de desenvolver um carro autônomo, os alunos precisam se adaptar às condições diversas das competições, pois estas condições são reveladas somente durante a competição, promovendo habilidades interpessoais no passo que os alunos precisam se regular como equipe e ajustar o carro em curto período de tempo. Normalmente, cada aluno apresenta uma ideia diferente de solução aos problemas enfrentados, tendo que realizar consenso e escolher a melhor solução para cada caso. Muitas vezes, ajustes diversos devem ser realizados durante a competição, exigindo conhecimentos de RE e RC, pois os alunos precisam ajustar os carros e modificar a programação do Arduino, sem auxílio do professor orientador.

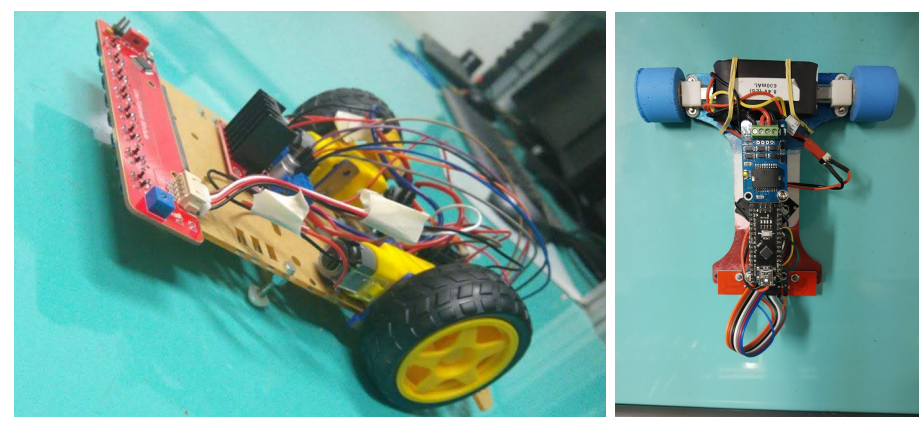

Figura 2. Robô Bob e Robô Napoleão

A pista de testes utilizada durante o desenvolvimento do projeto para testes diversos foi totalmente preta com o percurso feito em fita branca, como pode ser vista na Figura 1. Os robôs seguidores de linha, desenvolvidos em estilo Maker, totalmente desenhados e construídos à mão pela equipe, com o Chassi cortado numa impressora 3D, o primeiro nomeado como Bob pelos alunos e sua versão melhorada, desenvolvida após algumas competições locais, nomeado como Napoleão, podem ser vistos na Figura 2.

Todo o material didático construído ao longo do módulo CRSL foi disponibilizado no site do projeto, que conta com o detalhamento dos componentes do robô e sua construção. O curso online criado é composto por conhecimentos básicos do Arduino (o que é o Arduino, como montar um circuito simples usando Arduino, como fazer com que o Arduino controle a Ponte $H$, o que é uma Ponte $H$, entre outros), além de conhecimentos mais avançados, adquiridos através da vivência dos alunos, como o tópico que 
explica como escolher a melhor roda para o carro de acordo com o tipo de pista. Outro tema abordado no curso foi a Linguagem de Programação básica do Arduino, estendendo o curso disponibilizado no módulo LCI, detalhado na Subseção 4.1.

\section{Resultados}

O desenvolvimento dos alunos ao longo do projeto foi perceptível, além de ter sido avaliado através de pré-testes e pós-testes, mostrando que cerca de $80 \%$ do conteúdo lecionado foi assimilado pelos bolsistas. Além disso, foram realizadas entrevistas com os bolsistas, que deixaram claro a motivação por estar participando do projeto e competindo em eventos nacionais de robótica.

No início, dois alunos não apresentavam conhecimento sobre lógica de programação, um deles tinha um conhecimento básico. Ao final, todos os alunos conseguiram desenvolver algoritmos complexos para a manipulação do robô seguidor de linha, filtro de erros e ruídos das medições dos sensores, execução de movimentos complicados, como subir ladeiras e efetuar curvas acentuadas a altas velocidades, entre outros.

Os alunos desenvolveram desde habilidades interpessoais, aprendendo a lidar com discussões e desentendimentos internos, até habilidades de Raciocínio Computacional (RC) e Robótica Educacional (RE), ficando cada vez mais especializados em como solucionar problemas rapidamente, como fazer algoritmos de controle para Arduino, como trabalhar com erros de medidas, como ajustar o robô, entre outros. Além de demonstrarem empolgação com os resultados alcançados pela equipe, sugerindo participar de novas competições, buscando oportunidades para desenvolverem novos dispositivos e demonstrarem seus conhecimentos em mostras de ciências e tecnologias. A equipe participou de alguns eventos locais de Mostra de Robótica e interagiram com a comunidade científica acerca de suas conquistas e ideias.
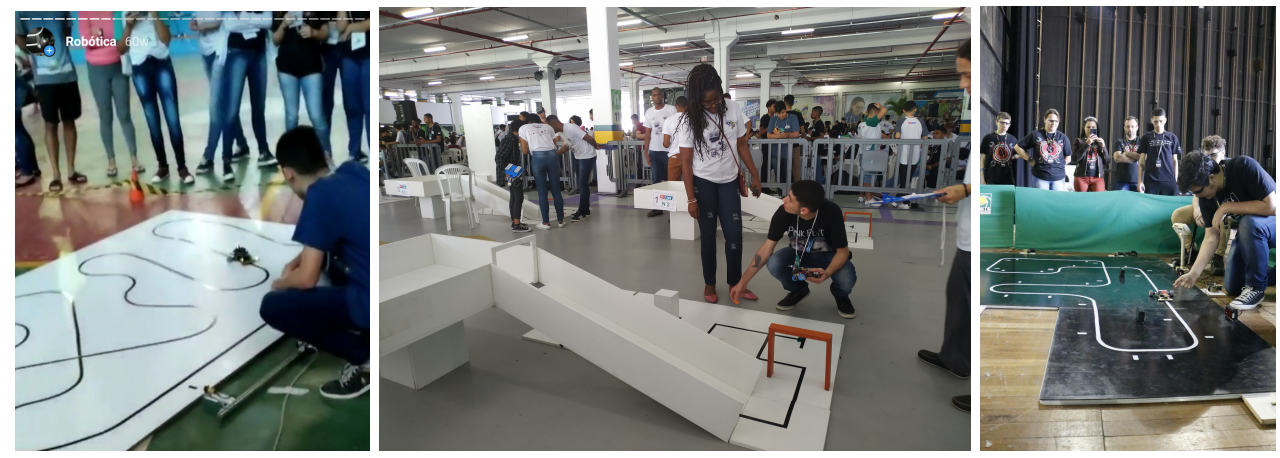

Figura 3. Participação RRC 2019, OBR 2019 e WCR 2019

Os alunos participaram de competições internas do IFBA, competições no âmbito do Estado da Bahia, como a Recôncavo Robot Challenge 2019 (RRC 2019), e também tiveram a oportunidade de levar seu robô, em constante aprimoramento, para competições nacionais, como a Olimpíada Brasileira de Robótica 2019 (OBR 2019) e o Winter Challenge RoboCore 2019 (WCR 2019). Na RRC 2019, eles competiram com Universidades Públicas e Privadas do Estado da Bahia e conquistaram a 3a colocação na categoria FollowLine, que é correspondente à categoria Robô Seguidor de Linha das demais competições. Na OBR 2019, a equipe conquistou o "Prêmio Dedicação", como equipe mais 
dedicada da competição, além de ter conquistado duas medalhas de ouro na modalidade teórica. No WCR 2019, mais amadurecida, a equipe competiu com universidades de todo o Brasil e logrou o 4ํ lugar da competição na categoria Robô Seguidor de Linha Jr, ver Figura3.

Os alunos terminaram a participação no projeto com conhecimentos avançados em programação de computadores e robótica. As habilidades do RC desenvolvidas ao longo do projeto foram a abstração e decomposição de problemas, generalização, consenso, sequenciação, avaliação e aprimoramento de soluções. Os alunos demonstraram também aumento nas habilidades sociais, aprendendo a trabalhar em equipe, dividir as tarefas e atingir soluções melhores mais rápido. Além de terem aprendido técnicas de ensino, organização de ideias e escrita.

"Participar do Laboratório de Robótica Inclusiva foi uma experiência interessante, pelo fato de eu ter começado a disputar em competições de robótica. Revisitar o trajeto que pude realizar com grande empenho e ajuda da professora orientadora e colegas de laboratório foi singular. Através deste projeto, pude me imaginar atuando como um pesquisador em Ciência da Computação, como se um passo tivesse sido dado em direção a este objetivo de vida". (Vinícius Melo - bolsista do LRI)

\section{Conclusão}

Durante o projeto do Laboratório de Robótica Inclusiva (LRI), três alunos do ensino médio técnico do IFBA participaram ativamente da construção de um robô Seguidor de Linha e da construção de um curso online sobre o assunto. No módulo Laboratório de Computação Inclusiva (LCI), um curso de Lógica de Programação foi montado com base no conteúdo programático da disciplina de Informática do curso técnico do IFBA, composto por vídeo-aulas e roteiros de aulas. No módulo Construção de Robô Seguidor de Linha (CRSL), um curso online sobre construção de Robôs Seguidores de Linha foi criado, com detalhamento do funcionamento do robô e seus componentes, com o intuito de disponibilizar à comunidade, público interno e externo do IFBA, acesso a todo conhecimento adquirido pelos alunos ao longo do projeto.

Os alunos participaram ativamente da construção de vídeo-aulas, roteiros de aulas e materiais didáticos diversos disponibilizados no site do projeto. A experiência foi enriquecedora para todos, alunos e professora. Os alunos desenvolveram habilidades do Raciocínio Computacional (RC) através do desenvolvimento das atividades de Robótica Educacional (RE) e puderam demonstrar estas habilidades na construção dos cursos online, construção dos robôs e na participação em competições e mostras de robótica. A RE se mostrou útil e estimulante para o desenvolvimento do RC dos alunos, deixando-os sempre empolgados e estimulados com o aprendizado adquirido ao longo projeto.

\section{Referências}

Cambruzzil, E. and Mendes de Souza, R. (2014). O uso da robótica educacional para o ensino de algoritmos. Anais do EATI - Encontro Anual de Tecnologia da Informação e Semana Acadêmica de Tecnologia da Informação, 1:40-47. 
Dargains, A. and Sampaio, F. F. (2015). Estudo exploratório sobre o uso da robótica educacional no ensino de programação introdutória. Master's thesis, Universidade Federal do Rio de Janeiro - UFRJ.

de Souza Pio, J. L., de Castro, T. H. C., and de Castro Júnior, A. N. (2006). A robótica móvel como instrumento de apoio à aprendizagem de computação. Simpósio Brasileiro de Informática na Educação - SBIE.

Díaz-Lauzurica, B. and Moreno-Salinas, D. (2019). Computational thinking and robotics: A teaching experience in compulsory secondary education with students with high degree of apathy and demotivation. Sustainability, 11(18):5109.

França, R. and Tedesco, P. (2015). Desafios e oportunidades ao ensino do pensamento computacional na educação básica no brasil. Workshop de Ensino em Pensamento Computacional, Algoritmos e Programação - CBIE.

Oliveira, E. and Araujo, A. L. (2016). Pensamento computacional e robótica: Um estudo sobre habilidades desenvolvidas em oficinas de robótica educacional. XXVII Simpósio Brasileiro de Informática na Educação - SBIE, page 530.

Oliveira, K. L., Oliveira, M., and Andrade, M. (2019). Pensamento computacional, robótica e educação: um relato de experiência e lições aprendidas no ensino fundamental i. In Anais do Workshop de Informática na Escola - WIE - CBIE, volume 25, page 1279.

Papert, S. (1980). Mindstorms: Children, Computers, and Powerful Ideas. Basic Books, Inc., USA.

Papert, S., Valente, J., and Bitelman, B. (1986). Logo: computadores e educação. Brasiliense.

Phadung, M., Namburi1, S., Dermrach, P., and Latekeh, I. (2018). Effects of enhancing computational thinking skills using educational robotics activities for secondary students. In 5th ICRIEMS, pages 613-618. Yogyakarta State University.

Piaget, J. (1976). Piaget and His School: A Reader in Developmental Psychology. Springer Berlin Heidelberg, Berlin, Heidelberg.

Santos, C. P., da Silva, D. ans Roque, A., de Lima, J. W., and Dal Ben, M. D. S. (2019). Tecendo espaços e experiências no campo da robótica educacional para fomentar o interesse de meninas pela área de computação. Anais do Workshop de Informática na Escola - WIE - CBIE, 25:9.

Schuhmacher, E. and Schuhmacher, V. R. N. (2017). Pensamento computacional, robótica educativa e aprendizagem significativa: a competência do sujeito invisível. IV World Congress on Systems Engineering and Information Technology.

Wing, J. (2006). Computational thinking. Communications of the ACM, 49:33-35.

Wing, J. (2008). Computational thinking and thinking about computing. Philosophical transactions Series A: Mathematical, physical, and engineering sciences, 366:37173725 . 